Arab World English Journal (AWEJ) Volume 12. Number1 March 2021

DOI: https://dx.doi.org/10.24093/awej/vol12no1.19

Pp.270 -292

\title{
Structured Input vs. Structured Output Task's Effects on the Acquisition of the English Causative Forms: Discourse-Level
}

\author{
Najat Alabdullah \\ Ministry of Education, Kuwait \\ Kuwait, Kuwait City \\ Email: najatalabdullah@gmail.com
}

Received: 11/8/2020

Accepted: 2/22/2021 Published:3/24/2021

Abstract:

This research paper presents a quasi-experimental empirical study investigating the effects of structured input and structured output tasks on the acquisition of English causative forms. This research is framed on VanPatten's (1996) input processing theory. The grammatical form chosen for this investigation is affected by a processing strategy called the First Noun Principle. There are three variables included that make this study significant. These variables are having participants that are young learners who speak Arabic as an L1 and using discourse-level instrumentation. These variables make this study significant because the studies that investigated the effectiveness of structured input practice with these variables are in the minority. The study's main questions are: (i) What are the short-term effects of structured input and structured output on the acquisition of English causative forms as measured with discourse-level interpretation tasks? (ii) What are the short-term effects of structured input and structured output on the learners' ability to acquire the English causative forms as measured with discourse-level production tasks? Participants were school-age learners (aged 12-13) from an Arabic background with Arabic as an L1 who studied English as a second language in Kuwait. A pre and post-test procedure was adopted in this study. Two instructional groups were created, which are: (i) structured input; (ii) structured output. Discourse-level tasks were used in the study to assess the effectiveness of the two instructional treatments. Results were analyzed using descriptive statistics and ANOVA. The main findings support the view that discourse-level structured input tasks are a useful pedagogical intervention in helping young L2 learners from an Arabic background with Arabic as an L1 to process, interpret and produce accurate English causative forms. The main findings have theoretical and pedagogical implications for language learning and teaching.

Keywords: Arabic L1, discourse-level instrumentation, first noun principle, processing instruction, young learners, structured input, structured output, causative form

Cite as: Alabdullah,N . (2021). Structured Input vs. Structured Output Task's Effects on the Acquisition of the English Causative Forms: Discourse Leve. Arab World English Journal, 12 (1) 270 -292.

DOI: https://dx.doi.org/10.24093/awej/vol12no1.19 


\section{Introduction}

The study presented in this research paper is a quasi-experimental empirical study conducted to investigate the effects of structured input (SI) activities and structured output (SO) tasks on acquiring the English causative forms. More specifically, the primary purpose of this investigation is to compare the effectiveness of structured input and structured output tasks on participants that are young L2 learners from an Arabic background with Arabic as an L1 and using interpretation and production discourse-level tests to measure this effectiveness. Although this study is a replication, it is a significant one because of the inclusion of three variables, which are having young L2 learners from an Arabic background with Arabic as an L1 and using discourse-level instrumentation, because the previous studies that investigated the effectiveness of structured input practice including these variables are in the minority. The main questions of this study arise from previous findings of different empirical studies that measured the effects of structured input activities and structured output tasks. The questions are: (i) What are the shortterm effects of structured input and structured output on the acquisition of English causative forms as measured with discourse-level interpretation tasks? (ii) What are the short-term effects of structured input and structured output on acquiring English causative forms as measured with discourse-level production tasks? This study is based on VanPatten's (1996) input processing theory. The grammatical form that will be investigated is the English causative form, that is affected by a processing strategy called the 'First Noun Principle.' The findings of this research paper will provide a solution to the learners' delay in acquisition of causative forms, which is caused by the First Noun Principle. The research design adopted and the results obtained in this study will be presented. The final part of this research paper will interpret the results and highlight implications, limitations, and possible avenues for further research.

\section{Literature Review}

\section{The Theory of Input Processing}

This study is framed on the input processing theoretical model. Input processing is a theory that was developed in the nineties by VanPatten (1996). Research and theory within this framework investigated what L2 learners process or do not process when exposed to language input. Processing according to VanPatten (2004) refers to "...processing refers to making a connection between form and meaning." ((VanPatten, 2004, p. 6)). The input processing theory also explains the conditions that allow L2 learners to make connections between a grammatical form and its meaning.

The input processing theory is concerned with (i) moment-by-moment connection of form to meaning and(ii) moment-by-moment computation of sentence structure during comprehension. Based on these two main constructs, the input processing theory consists of two main principles: The Primacy of Meaning Principle and The First Noun Principle.

The Primacy of Meaning Principle asserts that "learners process input for meaning before they process it for form" (VanPatten, 2004, p.14). For instance, when L2 learners listen to a sentence such as "Yesterday, Dana studied in the library," they would process Yesterday as an indicator of past tense before the ending - $e d$. This processing problem occurs because both the lexical item (temporal adverb) and the grammatical form encode the same semantic information. L2 learners, therefore, would rely (due to limited processing capacity) on the first lexical item they encounter in the sentence such as yesterday to process the sentence for its meaning instead 
of processing the grammatical form such as the -ed. The inability for L2 learners to initially connect form and meaning would reduce the amount of input processed, which is called intake "I use the term intake to refer to that subset of the input that has been processed in working memory and made available for further processing" ((Bill VanPatten, 2004, p. 7)). It would also cause a delay in the acquisition of verbal morphology (in this case, the processing of the -ed past tense marker).

Research within the input processing framework has consistently demonstrated the failure of L2 learners to make appropriate from-meaning mappings (Faerch \& Kasper, 1986; Klein, 1986; Fillmore, 1976; among others).

The First Noun Principle asserts that L2 learners usually process the first noun or pronoun they read or hear in a sentence as the subject of that sentence. According to this principle, "learners tend to process the first noun or pronoun they encounter in a sentence as the subject/agent' (VanPatten, 2004, p.18). This processing behavior would often lead to a misinterpretation of the sentence L2 learners hear or read. For example, in a sentence such as "The student was rewarded by the teacher," L2 learners would misinterpret the sentence as if The student rewarded the teacher. The lack of comprehension of this sentence causes a delay in the acquisition.

Evidence for this processing strategy comes from several studies. LoCoco (1987) measured learners' comprehension of oral and written sentences containing word order in German and Spanish. One-hundred and fifty-one university students participated in the study. Their L1 was English. Seventy-three were studying Spanish, and seventy-eight were learning German. The experiment included an aural comprehension task and a written comprehension task. The tasks included sentences with a variety in word order, and participants had to establish 'who did what to whom.' Also, responses were classified as correct or incorrect.

The results of the study indicated that word order in both languages played a vital role in the participants' interpretation and comprehension of sentences. Sentences with the word order subject-verb-direct object were nearly always interpreted correctly. However, students made many more mistakes in interpreting other sentences in which the first noun they encountered in the sentence was not the subject. For example, the following sentence Den lastwagen schiebt der junge (LoCoco, 1987) means in English 'the boy pushes the truck.' However, the object was written before the subject like the following sentence 'the truck pushes the boy.' Because of this particular word order in the sentence, $76 \%$ of the students misinterpreted it, by processing the sentence as 'the truck who pushes the boy.'

In another study investigating the effects of the First Noun Principle, VanPatten and Wong (2004) conducted an empirical study in two universities in the United States. The target grammatical form under investigation was the French causative form. In a sentence like "JeanPaul fait lire le journal a Henri (Jean-Paul makes to read the newspaper to Henri/ Jean-Paul makes Henri read the newspaper)" (VanPatten \& Wong, 2004, p.104), most participants would process Jean-Paul as the one who reads the newspaper and not Henri and therefore misinterpret the meaning of the sentence because of the First Noun Principle. 
Participants were undergraduates enrolled in French courses who did not receive any formal instruction on the French causative form before the experiment. They were distributed into three groups: the first group with twenty-nine subjects received processing instruction (PI); the second with twenty students received traditional instruction (TI), and the third with twentyeight subjects as a control group received no instruction. Pre and post-tests interpretation and production tests were administered. The results showed that only the processing instruction group improved significantly in the interpretation test from pre to post-test. The traditional instruction group did not. However, for the production test, both processing instruction and traditional instruction groups improved almost equally.

In the current study, the acquisition of English causative forms will be investigated. This syntactic feature is also affected by the First Noun Principle (FNP). This universal and default processing strategy is used by L2 learners which causes misinterpretations and delays in the acquisition. The present study will make use of structured input practice and investigate its effectiveness compared to structured output practice in enabling young L2 learners from an Arabic background with Arabic as an L1 to circumvent this processing principle and ensure that they are in the best position to process word order correctly when exposed to English causative forms.

\section{Processing Instruction}

Processing instruction is a pedagogical intervention derived from the input processing theory, and it aims at facilitating the cognitive processes by which L2 learners make form-meaning connections and, or compute sentence structure during comprehension. For example, L2 learners prefer to process lexical items first, before grammatical items when both items encode the same semantic information (Benati, 2010). Processing instruction has been described in previous work (Benati, 2019; VanPatten, 2015). The main characteristic of the processing instruction is that it uses a particular type of input practice (structured input) to push learners away from non-optimal processing principles so that they are more likely to process input correctly and appropriately. Processing instruction is mainly concerned with the processing of morpho-phonological units in input strings and the development of underlying linguistic representation. Most simply, one of the primary objectives of processing instruction is to ensure that L2 learners process grammatical forms and structures (one at a time) accurately and efficiently in the input they receive, "The main purpose for Processing Instruction is to guide and focus L2 learner's attention when they process input; to instill in them target language appropriate processing strategies." (Benati \& Lee, 2010, p.32), "The main purpose of Processing Instruction is, then, to help L2 learners to make appropriate form-meaning connections and parse sentences correctly so that as a result they develop their internal linguistic system for the target language" (Benati \& Lee, 2010, p.33). Processing instruction consists of two main components: (i) L2 learners are given explicit information about a linguistic structure or grammatical form and the particular processing principle which may have a negative impact on their picking up of the grammatical form or structure while processing the language; and (ii) L2 learners are pushed to process (not produce) the target grammatical form or structure during structured input (SI) activities. In structured input activities, the input is structured so that L2 learners can process the grammatical markers that otherwise would not be processed, "SI activities require L2 learners to process form correctly in order to get meaning. SI activities are designed to ensure that learners are indeed making the proper form-meaning connections" (VanPatten, 2004, p.198). 


\section{The Effects of Structured Input Activities}

Structured input practice pushes L2 learners to process the grammatical form or structure during activities in which the input is manipulated in particular ways. Hence, learners become dependent on the grammatical form to get meaning. In structured input tasks, the input is manipulated in a special way to push learners towards being dependent on the grammatical form to reach the meaning. Therefore, processing instruction "pushes learners to abandon their inefficient processing strategies for more optimal ones so that better form-meaning connections are made" (Wong, 2004, p.35).

The positive effects of structured input practice have been measured in many empirical studies (Benati, 2019) and generalized to different learners' backgrounds and L1s, forms/structures (verbal and nominal morphology), processing strategies, and languages (both romance and nonromance languages). Structured input practice has been compared to output-based instruction (including traditional instruction) using offline and online measurements.

VanPatten and Oikkenon (1996) originally investigated the effects of processing instruction components. Three groups were compared: explicit instruction only group, structured input practice only group, and full processing instruction group. The results showed that the processing instruction and the structured input groups made similar gains on the other hand, the explicit information only group did not. The main findings of this study indicated that the structured practice is the causative factor in explaining the positive results of processing instruction. Benati (2004a, 2004b), Farley (2004), and Wong (2004) replicated this original study and obtained similar findings. Lee and Benati (2007) established that performing structured input activities is an effective treatment for helping Italian native-speakers improve their grammatical gains with the Japanese past tense marker. They made a comparison between the results of structured input practice with no explanation and the results of traditional output instruction. The structured input group outperformed the traditional instruction group on the interpretation posttest whereas, both groups made equal gains on the production post-test.

Wong and Ito (2018) compared changes in processing patterns between L2 learners receiving structured input and traditional instruction on acquiring the French causative. In this pre-and post-test experimental study, a dichotomous scene selection eye-tracking activity was utilized to measure eye movement patterns and accuracy in selecting pictures while learners were processing auditory sentences. The results indicated that the structured input group gained higher accuracy scores than the traditional instruction group. Also, a change in eye movement was observed in learners only after the processing instruction training and not after the traditional instruction training.

Benati and Batziou (2019a, 2019b) have explored the discourse and long-term effects of structured input and structured output practice when delivered in isolation or combination on the acquisition of the English causative forms. These studies included young (10-12) Greek learners and adult (18-20) Chinese learners. The results of both studies were similar and showed that L2 learners who received the structured input instructional training benefitted more than L2 learners receiving structured output instructional training. In both studies, structured input practice alone was sufficient to improve learners' performance on both interpretation and production discourse tests containing English causative forms regardless of their age or native language. These 
findings support the Age Hypothesis, which suggests that "PI will be just as effective an intervention with young learners as it is with older learners" (Benati \& Lee, 2008, p. 168). Also, these findings support the Native Language Hypothesis, which suggests that "PI will be effective for instilling target language specific processing strategies, no matter the native language of the learners" (Benati \& Lee, 2008, p. 166). The effectiveness of structured input practice has been generalized to different learner backgrounds and L1s, grammatical forms/structures (verbal and nominal morphology), processing strategies (Primacy of meaning principle and its corollaries), and languages (romance languages and Japanese).

Benati (2020) investigated the effects of structured input and traditional instruction on accuracy when measured by an eye-tracking picture selection task among Chinese native speakers learning English. A pre and post-training design was adopted. An eye-tracking picture selection task was used for assessment. Students had to listen to a sentence through a headphone, answer by choosing a picture from the two images displayed, decide on who did the action in every sentence, and then move on to the sentence after it. The results showed that the improvement of the structured input group reached $70 \%$ in the learners' ability to process and interpret the causative form. In contrast, the traditional instruction group didn't improve their performance at all. Structured input treatment also increased the learners' gaze towards the correct picture in the tests compared to the traditional instruction. Therefore, the results of this eye-tracking assessment task indicated that the structured input group achieved significantly higher accuracy.

\section{Research Measuring Discourse-Level Effects}

There is a huge amount of research on processing instruction (Benati \& Lee, 2009; Benati \& Lee, 2010), which provides evidence that learners who received this type of instruction performed significantly better on sentence-level interpretation tasks than learners receiving other kinds of instruction such as traditional instruction (paradigmatic explanations of rules followed by drill practice) or less mechanical output-based interventions to grammar instruction (e.g., structured-output tasks, more later). Also, processing instruction can cause equal improvement compared to output-based approaches in learners' performance in different sentence-level production tasks (oral and written). However, few studies have investigated whether processing instruction effects can be measured on discourse-level interpretation and production tasks.

Benati and Lee (2010) assessed the effects of processing instruction using discourse-level interpretation tasks. They showed that processing instruction on English past tense led to improved scores on sentence-level and discourse-level interpretation task. Benati, Lee, and Hikima (2010) showed that processing instruction on Japanese passive constructions led to improved scores on two different discourse-level interpretation tasks (immediate effects), both presented aurally. The processing instruction group also made measurable gains in the discourselevel task. These results confirm Lee's original hypothesis "PI will yield significant improvement on discourse level interpretation tasks"' (Lee, 2004, p.322)

Concerning production, VanPatten and Sanz (1995), Sanz (1997, 2004), and Sanz and Morgan-Short (2004) showed that processing instruction on Spanish direct object pronouns led to improved scores on oral and written structured interviews in addition to oral and written video-based retellings. Other types of discourse-level assessment tasks have been used in 
processing instruction research. Cheng (2002, 2004) found positive effects for processing instruction on Spanish copular verbs using a picture-based guided composition. Benati, Lee, and McNulty (2010) used a guided composition and found a positive effect for processing instruction on the Spanish subjunctive after cuando. Empirical findings from these studies have indicated that processing instruction is effective not only at the sentence level but at discourse level production tasks (immediate and short-term effects). There is a minimal amount of research conducted to examine the impact of processing instruction using discourse-level instrumentation. Therefore, future research may investigate how learners process and produce discourse containing different target grammatical forms and whether these effects are durable. Therefore, in this study, discourse-level instrumentation was used.

Hence, this study is significant because the studies that investigated the effectiveness of structured input practice on young L2 learners from an Arabic background with Arabic as an L1 by using discourse-level instrumentation is in the minority. Thus, replications including these three variables (young, Arabic L1, and discourse-level instrumentation) are very much needed because they will allow us to include a larger population of learners on which the positive impact of structured input practice has been experimented and confirmed. Therefore, although this study is a replication yet, it is an important one as its purpose is to provide more empirical evidence for the effectiveness of structured input practice in improving the ability of young L2 learners from an Arabic background with Arabic as an L1 in processing, interpreting, and producing the English causative form using discourse-level instrumentation. Moreover, this study will contribute to the field by providing additional empirical evidence for the so-called Age Hypothesis and Native Language Hypothesis (Benati \& Lee, 2008).

\section{Methods}

\section{Motivation and Research Questions}

Overall, the empirical work measuring structured input practice has indicated that it is an useful pedagogical intervention for grammar instruction. A growing body of research (Benati, 2019, Benati and Batziou, 2019a, 2019b) has compared discourse-level effects of structured input practice versus structured output practice on acquiring various linguistic features across different romance and non-romance languages. Most of these empirical studies have involved adult learners.

Despite the existing research within this investigation line, there are still several issues that have not been addressed: (a) Would structured input and structured output practice have beneficial effects among L1 Arabic school-age learners? (b) Would L1 Arabic school-age learners receiving structured input practice be able to interpret and produce discourse containing English causative forms?

There are two primary aims for this study:

a) To compare and contrast two instructional treatments: structured input (SI) practice versus structured output (SO) practice, on the acquisition of English causative forms by L1 Arabic school-age learners;

b) To measure short-term effects of structured input practice and structured output practice on discourse-level interpretation and production tasks.

Based on these aims, two specific questions were formulated: 
Q1: What are the short-term effects of structured input and structured output on the acquisition of English causative forms as measured with discourse-level interpretation tasks?

Q2: What are the short-term effects of structured input and structured output on the acquisition of English causative forms as measured with discourse-level production tasks?

\section{Subjects and Procedures}

To address the two main questions of this study, a quasi-experimental classroom study was carried out. Before conducting the experiment and collecting the data, the American University of Sharjah's Institutional Review Board (IRB) approval was obtained. Two existing classes in a school in Kuwait were used to collect data. Although no randomization procedure was adopted, yet participants in these classes are usually distributed by the administration to include students with high, moderate, and low school performance, including language proficiency level in English. This is done to avoid having a class with only high achievers and another class with only low achievers.

The original pool was reduced to twenty-seven subjects (L1 Arabic) enrolled in an English course in a public school in Kuwait. They were young female learners (aged 12-13). The final pool consisted of the following two groups: SI $(n=15)$; SO $(n=12)$. Each group was taught separately. No control group was used. Instruction lasted for two hours over three days in a pretest and post-test design measuring immediate effects of the two instructional treatments. The three-day treatment was designed and implemented specifically for this study. The English causative was neither a structure included in the curriculum pupils were currently studying nor part of previous English courses they studied. Therefore, it was assumed that they had not received any formal instruction related to the targeted grammatical form before the experiment.

Participants who scored over $40 \%$ on the pre-tests (administered before the beginning of the instructional treatment) were excluded from the final data pools. Moreover, only the participants who completed all the phases of the experiment were counted in the final data analyses. The instructor was the researcher. She acted as a facilitator and delivered the instructional treatment in both classes (see an overview of the study in Table one).

Table 1.Overview of the study

\begin{tabular}{lc}
\hline Phase & Description \\
\hline Pre-tests & Discourse-level interpretation and production tests \\
\hline $\begin{array}{l}\text { Instructional Period } \\
\text { Over } 3 \text { days }=2 \text { hours } \\
\text { instruction }\end{array}$ & Structured input (SI) vs. Structured output (SO) \\
\hline Post-tests (immediate) & Discourse-level interpretation and production tests
\end{tabular}

This study got an ethical approval from the university and the Ministry of Education in Kuwait. To get consent from The Ministry of Education in Kuwait, all the materials used in the experiment were translated and submitted for consideration.

\section{Target Grammar Feature}

The targeted grammatical feature selected for the current study was the passive English causative form. It was picked because it is affected by the First Noun Principle (VanPatten, 1996, 
2002, 2004). Due to this principle, L2 learners tend to give agent status to the first pronoun or noun they read or hear in a sentence. For instance, in the sentence Jury had her dress mended last Monday, learners would process Jury as the person who repaired the dress. This default processing strategy would cause misunderstanding and delay in the acquisition of the target feature and word order pattern. The main goal of structured input is to aid learners in parsing English causative correctly and appropriately. Previous studies in the input processing framework demonstrated evidence for the positive effects of structured input in circumventing the First Noun Principle and helping learners to correctly interpret and produce sentences containing the target feature (Benati \& Lee, 2010).

\section{Instructional Treatments}

Two instructional treatments were used in the present study. The materials were adopted from the materials used in a previous study (Benati \& Batziou, 2019a, 2019b). They were balanced in terms of the activity types (seven), the number of target features (seventy targets), the duration of activities, the vocabulary items (high frequency and familiar things), and the use of visuals. The activities were provided to learners on worksheets. No explicit instruction concerning the targeted grammatical form was given, and participants were given equal time to complete their activities in both instructional treatments. At no time did the participants receive either explanation or feedback about the target grammatical form. Participants in the two groups were only informed whether they were right or wrong, but no explanation was given at the end of each activity.

\section{The Structured Input (SI) Treatment}

Structured input (SI) is the practice component of processing instruction. During structured input activities, students are pushed to process the targeted grammatical feature through tasks with an input that is manipulated in a specific way. Hence, learners become dependent on the grammatical form or the structure to get meaning, "L2 Learners are now pushed to process the form or structure during activities in which the input is manipulated in particular ways to get learners to become dependent on form to get meaning. We refer to these as structured input activities." (Benati \& Lee, 2010, p.36). Structured input activities created for this study were referential. Referential tasks are tasks that have a correct or wrong answer, also for the learner to get meaning he/she must rely on the targeted grammatical form. The structured input treatment, developed for this experiment, contained in total seventy target items in seven activities (see sample in Figure one). It was designed according to the following guidelines, which were originally produced by VanPatten and Sanz (1995) for creating structured input tasks "...a. Present one thing at a time. b. Keep meaning in focus. c. Move from sentences to connected discourse. d. Use both oral and written input. e. Have the learners do something with the input. f. Keep the learner's processing strategies in mind." (Benati, 2013, p.37). More specifically, the activities included were aural and written input. Tasks were structured in a way that enables L2 learners to rely on the causative structure to understand the meaning in the input correctly. Also, they were developed to aid learners to circumvent the First Noun Principle by manipulating word order and contrasting passive (English) causative structures to SVO order active structures where the first noun was the causer/agent of the action. All tasks were meaningful and communicative, and participants were asked to correctly interpret the input. Moreover, tasks that require producing the targeted grammatical feature were excluded. 

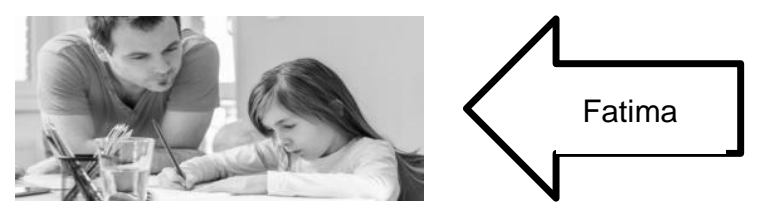

A) Fatima had her homework written.

B) Fatima wrote her homework.
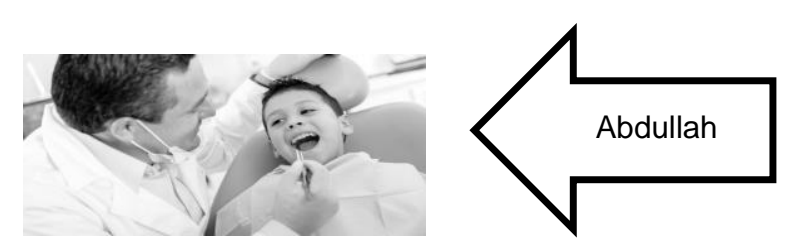

2:

A) Abdullah checked his teeth.

B) Abdullah had his teeth checked.

Figure 1. Sample of a SI activity

\section{The Structured Output (SO) Treatment}

The structured output treatment contained in total seventy target items in seven activities (see example in Figure two) that were developed according to the following guidelines provided by Lee and VanPatten (1995) to create structured output tasks "a. Present one thing at a time. b. Keep meaning in focus. c. Move from sentences to connected discourse. d. Use both written and oral output. e. Others must respond to the content of the output. f. The learners must have some knowledge of the form or structure." (Lee \& VanPatten, 1995, p.121) Learners included in the final pool had limited knowledge of the target grammatical form as only learners who scored up to $40 \%$ of the maximum score available in the pre-tests were included in the final pool. Each activity contained two to three steps that pushed participants to produce oral and written output. All tasks were communicative and meaningful, and mechanical practice was excluded. They were working in pairs to complete each task. Each activity included familiar items, and a list of vocabulary items was also provided. Structured output has two characteristics: "involves the exchange of previously unknown information; requires learners to access a particular form or structure in order to express meaning", (Lee \& VanPatten, 1995, p.21)

\footnotetext{
Step 1. Write at least six winter activities that you had to do last winter. Write down how many you did yourself and how many you had done by someone else.

Example: "I drank hot chocolate, but I had it prepared by my mother, I was too busy"

Step 2. Write at least six summer activities that you had to do last summer. Write down how many you did yourself and how many you had done by someone else.

Example: "I ate ice cream, but I had it bought by my father, I don't know much was it."
}

Figure 2. Sample of a SO activit

\section{Assessment Tasks and Scoring}

A pre-test and post-test design was used. There were two versions of the interpretation and production tests. Pre-tests were administered before the instructional period to both experimental groups. Immediate post-tests were distributed at the end of the instructional period. The assessment tasks consisted of a discourse-level interpretation task and a discourse-level production task. The two versions of each assessment test were developed and balanced in terms of difficulty and vocabulary. 
The discourse-level interpretation task (see Figure three, Appendix B) was developed to measure the learners' ability to interpret correct English passive causative forms when these forms are embedded in discourse. Participants had to listen to a story presented in three segments, each segment included three target items and two distractors. In total, the activity had nine target items and six distractors. Also, a booklet was made for the discourse-level interpretation task. Participants heard the story segment once, then turned to the appropriate answer sheet (it included images showing two different characters doing the same thing) to decide who was performing the action or opt for Not Sure if they could not understand who the agent was. Participants received one point for each correct selection and 0 points for each incorrect one.

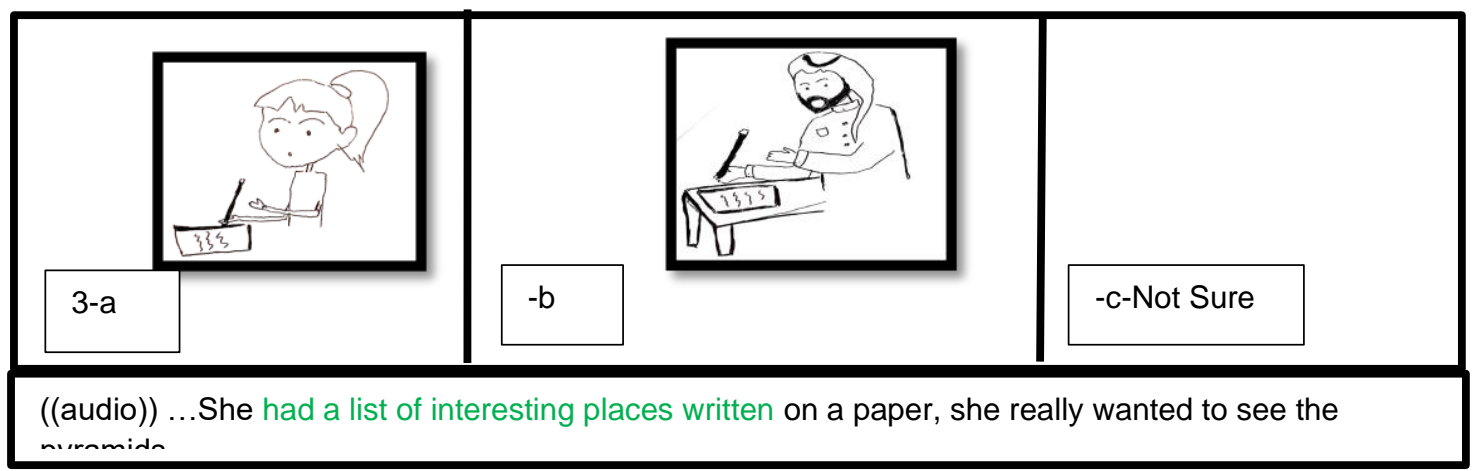

Figure 3. Sample of a discourse-level interpretation task

The discourse-level production task (see Figure four, Appendix A) was developed to measure learners' ability to produce correct English passive causative forms at discourse-level (text reconstruction). It had five target items (which are instances of the English causative form). Learners had to review some essential vocabulary items before the beginning of the assessment. The instructor played the audio of the story, which was read by a native English language speaker, at an average pace providing information about the context at the beginning. As the instructor played the audio of the story, she also projected it on the whiteboard to enable the participants to read and listen at the same time. After that, participants were asked to re-write the story they listened to. They had five minutes to reconstruct the story with the aid of some prompts. For each right use of the target structure, one point was given. On the other hand, if the participants had used the right structure of the target item but the incorrect form of the verb (i.e., an infinitive instead of a participle), they were given half a point. The maximum score for the discourse level tasks was five points as this was the maximum number of target items learners needed to complete the story.

Then re-write the story you heard.

"Amal is a very good girl. She always takes good care of her bedroom and makes sure that it is clean and tidy. However, during the exams she becomes so busy, so her mother helps her..." 
Figure 4: Sample of a discourse-level production tas

\section{Data Analysis}

One-way ANOVA was conducted on the raw scores for the interpretation and the production-discourse level tasks to assess whether there were any statistically considerable differences among the class means of any of the pre-test's measures. A repeated-measures ANOVA was carried out on the raw scores of both the interpretation and the production discourse-level tasks. The between-subjects factor was 'Treatment' (SI vs. SO), and the withinsubjects factor was 'Time' (pre-tests vs. post-tests).

\section{Results}

\section{iscourse-Level Interpretation Data}

A one-way ANOVA was carried out on the two groups pre-test scores (SI and SO). The one-way analysis indicated no significant differences among the two groups before instruction $(F$ $(1,27)=1.346 p=.89)$. If any differences were found after instruction, they will be attributed to the effects of the instructional treatments. In Table 2, the descriptive statistics for learners' performance on the discourse-level interpretation tasks are presented. They show the means of the two groups in the discourse-level interpretation task (pre-test and immediate post-test). The structured input group improved from pre-test to post-test scores. The structured output group did not.

Table 2. Interpretation discourse-level task (descriptive statistics)

$$
\text { Pre-test Post-test }
$$

\begin{tabular}{llllll} 
Variable & $\mathrm{n}$ & Mean & SD & Mean & SD \\
\hline SI & 15 & 2.1 & 0.500 & 3.4 & 0.650 \\
& & & & & \\
\hline SO & 12 & 2.2 & 0.340 & 1.8 & 0.560
\end{tabular}

A two-way ANOVA was performed on the raw scores of the discourse-level interpretation task. The results showed a significant main effect for Treatment $(F(1,27)=$ $34.358, p<.001)$; a considerable main effect for Time $\mathrm{F}(1,27)=12.130, p<.001$; and significant interaction between Treatment and Time $F(1,27)=6.235, p<.001$.

The results of the ANOVA and the descriptive statistics indicated that only the subjects in the structured input group gained (from pre-test to post-test) in their ability to interpret the target grammatical forms presented at the discourse-level.

\section{Discourse-Level Production Data}

A one-way ANOVA was conducted on the two groups pre-test scores. It showed no significant differences among the two instructional groups (SI and SO) before instruction ( $F$ $(1,27)=2.139 p=.103)$. If any differences were found after instruction, they will be attributed to 
the effects of the instructional treatments. In Table 3 below, the descriptive statistics for learners' performance on the discourse-level production tasks are presented. They showed the means of the two groups in the discourse-level production task (pre-test and immediate post-test). Once again, like the interpretation task, the structured input group was the only group improving from pre-test to post-test scores.

Table 3. Production discourse-level task (descriptive statistics).

$$
\text { Pre-test Post-test }
$$

\begin{tabular}{llllll}
\hline Variable & $\mathrm{n}$ & Mean & SD & Mean & SD \\
SI & 15 & 0.4 & 0.100 & 1.2 & 0.150 \\
& & & & & \\
\hline SO & 12 & 0.3 & 0.050 & 0.3 & 0.100
\end{tabular}

A two-way ANOVA was carried out on the raw scores of the discourse-level production task. The results showed a significant main effect for Treatment $(F(1,27)=23.376, p<.003)$; a considerable main effect for Time $\mathrm{F}(1,27)=10.129, p<.001$; and significant interaction between Treatment and Time $F(1,27)=6.237, p<.001$. The results from the ANOVA and the means of both groups in the post-test indicated that only subjects in the structured input group gained in their ability to produce the target grammatical forms presented at the discourse-level.

\section{Discussion}

This study aimed to investigate the effects of structured input tasks and structured output tasks on the acquisition of the English causative form, including young L2 learners from an Arabic background with Arabic as an L1, using both interpretation and production discourselevel tasks. This makes this study significant and vital because the studies that investigated the effectiveness of structured input practice, including these variables, are in the minority.

The findings from the interpretation discourse-level task provide empirical support for the view that structured input practice is better than structured output practice in changing the way learners process input. Structured input practice is a better pedagogical intervention for ensuring learners' correct interpretation of English causative forms, including young L2 learners from an Arabic background with Arabic as an L1 receiving discourse-level instrumentation. One of the possible explanations for the results obtained in the interpretation discourse-level task is that the structured input practice pushed learners to abandon their default processing strategy, the First Noun Principle, and process word order correctly in interpreting English causative forms.

The main findings from the production discourse-level task indicated that structured input practice has a positive effect on the ability of young L2 learners from an Arabic background with Arabic as an L1 to produce the target feature at discourse-level also. The statistical analysis showed that only structured input practice made statistically significant gains from the pre-test to the immediate post-test. A possible explanation of this particular finding is that structured input practice has altered the way L2 learners processed input and must have had the following effects: 
(i) a positive effect on L2 learners' developing system; (b) a subsequent impact on what L2 learners in this group could access for production.

The findings from the interpretation and the production discourse-level tasks are in line with previous research findings measuring the effects of structured input practice (Benati \& Lee, 2015; Benati, 2017). Overall, the results are consistent with the original study (VanPatten \& Cadierno, 1993).

This view is further supported by the fact that in this study, learners receiving structured input practice could produce the targeted grammatical form by receiving discourse-level instrumentation, which is a less controlled situation, instead of sentence-level instrumentation. While the structured input treatment seems to be successful at circumventing processing problems and consequently having an impact on learners' developing system, the structured output treatment was not successful at helping L2 learners to interpret and produce the target feature at the discourse-level. The discourse-level production task used in this study was not used as a skill measure. The primary purpose of this production task was to see if L2 learners can access newly developed knowledge. Although with a note of caution, considering the small sample of the population in this study, the structured input practice was once again successful in helping L2 learners to develop their underlying knowledge.

\section{Conclusion}

Generally, the empirical work measuring structured input practice has shown that it is an useful pedagogical intervention for grammar instruction (Benati \& Lee, 2015; Benati, 2017; VanPatten \& Cadierno, 1993). However, minimal studies have investigated whether processing instruction effects can be measured on discourse-level interpretation and production tasks. Also, the majority of these empirical studies have involved adult participants. Therefore, this study included discourse-level instrumentation and L1 Arabic school-age learners to investigate the effectiveness of structured input tasks with these variables in providing a solution to the delay in acquisition of the causative form, which is caused by the First Noun Principle. Also, to investigate the effectiveness of discourse-level structured input tasks in enabling these participants to interpret and produce the grammatical feature targeted.

The results of the interpretation discourse-level task indicated that structured input helps learners process the English causative form correctly and appropriately in an immediate posttest. The structured input instructions were more effective than the structured output instructions in enabling participants to interpret the targeted grammatical forms embedded in discourse. The results of the production discourse-level task indicated that the instructional group structured input performed better than the structured output only group in an immediate post-test. The structured input instructions were more effective than the structured output instructions in helping the students produce the target grammatical forms embedded in discourse.

\section{Implications}

In general, the primary findings of this study make several theoretical and pedagogical contributions to the ongoing debate on the impact of structured input and structured output practice. 
Firstly, the results of this quasi- experimental study confirm the crucial role of structured input as an effective pedagogical intervention created to alter processing problems such as the First Noun Principle. Structured output alone is not successful in bringing similar effects to those brought by structured input in interpretation discourse-level tasks. The findings of this research reaffirm the significance of input-based practice as a critical pedagogical tool in language teaching contributing to the view that input practice should precede output practice. Structured output practice did not affect the interpretation of language discourse.

Secondly, structured input effectively develops learners' ability to access the developing system for speech production. L2 learners in the structured input practice group produced English causative forms in language discourse by using discourse-level task, which is a less controlled situation, instead of sentence-level tasks. Structured output practice did not affect the production of language discourse.

Thirdly, the main results from this study provide new short-term effects evidence of structured input practice effectiveness on school-age learners from an Arabic background with Arabic as an L1. Given that very little research has investigated the effectiveness of structured input tasks on young L2 learners from an Arabic background with Arabic as an L1 hence, the findings of this study are highly significant as they allow us to include a larger population of learners on which the effectiveness of structured input practice has been observed. In this respect, the overall findings from this study lend support to several hypotheses formulated within the processing instruction research framework. The positive results reached by this study support the so-called Age Hypothesis (Benati \& Lee, 2008). Confirming that structured input is an effective intervention with young learners just as it is with older learners. It also supports the socalled Native Language Hypothesis (Benati \& Lee, 2008). This research contributes to the expanding of the Native Language Hypothesis by adding Arabic, a non-western language, to the current list of languages on which the effectiveness of structured input practice has been observed.

\section{Limitations and Further Research}

Despite the positive outcomes of this research, there are few limitations. There is no control group (due to attrition and other practical issues) is a methodological limitation. Future studies should replicate this study using a control group. Also, no randomization procedure was applied as existing classes were used. However, in this particular school context, students were equally distributed by the administration, considering high, moderate, and low school performance and English language proficiency.

The sample of the population is relatively small for a quasi-experimental study. Future research should use a larger sample to generalize these findings.

This study measured the short-term effects of structured input and structured output on the interpretation and production of discourse-level tasks. Future research should aim at measuring long-term effects. In this study, delayed post-tests were not used because of the school closure due to the current circumstances.

Overall, research measuring the effects of structured input practice should use more spontaneous tasks that include time pressure, reaction time measures and do not allow learners to 
Arab World English Journal (AWEJ) Volume 12. Number 1. March 2021

Structured Input vs. Structured Output Task’s Effects on the Acquisition

Alabdullah

monitor their responses. This research might also consider the role and effects of structured input and structured output practice with or without explicit information.

\section{Acknowledgement}

This study was funded by the Ministry of Education in Kuwait.

\section{About the Author}

Najat Alabdullah pursued her Bachelor degree in English Language linguistics from Kuwait University (2012). She worked as a translator in the Foreign Relations Department in the Ministry of Social Affairs in Kuwait (2013-2016). Also, she worked as a teacher in the Ministry of Education in Kuwait (2012-2013/2016-2021). In addition, she pursued her MA TESOL from the American University of Sharjah (2018-2020). https://orcid.org/0000-0001-8075-4504

\section{References}

Benati, A. (2004a). The effects of structured input and explicit information on the acquisition of Italian future tense. In B. VanPatten (Ed.). Processing instruction: Theory, research, and commentary, (pp.207-255.) Mahwah, NJ: Erlbaum.

Benati, A. (2004b). The effects of processing instruction and its components on the acquisition

of gender agreement in Italian. Language Awareness 13, 67-80. Doi:

$10.1080 / 09658410408667087$

Benati, A. (2010). Grammar Instruction and Processing Instruction in second language acquisition. Journal of Applied Linguistics, 26, 43-58.

Benati, A. (2013). Issues in Second Language Teaching. Sheffield, UK: Equinox Publishing Ltd. DOI: https://doi.org/10.1111/modl.12198

Benati, A. (2017). The role of input and output tasks in grammar instruction: Theoretical, empirical and pedagogical considerations. Studies in Second Language Learning and Teaching, 7(3), 377-396. DOI: 10.14746/ssllt.2017.7.3.2

Benati, A. (2019). Classroom-oriented research: Processing Instruction (findings and implications). Language Teaching, 52(3) 343-359.

DOI: http://dx.doi.org/10.1017/S0261444817000386

Benati, A. (2020). The effects of structured input and traditional instruction on the acquisition of the English causative passive forms: An eye-tracking study measuring accuracy in responses and processing patterns. Language Teaching Research. DOI: http://dx.doi.org/10.1177/1362168820928577

Benati, A., \& Batziou M. (2019a) The effects of structured-input and structured-output tasks on The acquisition of English causative. International Review of Applied Linguistics in Language Teaching, 57, 265-288. https://doi.org/10.1515/iral-2016-0038

Benati, A., \& Batziou M. (2019b) Discourse and long-term effects of structured-input and structured-output tasks in combination and isolation on the acquisition of passive English causative forms. Accepted and forthcoming in Language Awareness, 28(2), $1-18$.

Benati, A., \& Lee, J. (2008). Grammar acquisition and processing instruction: Secondary and cumulative effects. Bristol: Multilingual Matters.

Benati, A., \& Lee, J. (2010). Processing instruction and discourse. London, England: Continuum. 
Benati, A., Lee, J., \& Hikima, N. (2010). Exploring the effects of processing instruction on discourse-level interpretation tasks with the Japanese passive construction. In A. Benati, \& J. F. Lee (Eds.), Processing instruction and discourse (pp.148-177). London, England: Continuum.

Benati, A., Lee, J., \& McNulty, E. (2010). Exploring the effects of processing instruction on a discourse-level guided composition with the Spanish subjunctive after the adverb cuando. In A. Benati, \& J. F. Lee (Eds.), Processing instruction and discourse (pp.97-147) London: Continuum.

Benati, A., \& Lee, J. (2015). Processing instruction: New insights after twenty years of theory, research and application [Special issue]. International Review of Applied Linguistics, 53(2), 87-257.

Cheng, A. C. (2002). The effects of processing instruction on the acquisition of ser and estar. Hispania, 85, 308-323.

Cheng, A. C. (2004). Processing instruction and Spanish ser and estar: Forms with semanticaspectual value. In B. VanPatten, (Ed.), Processing instruction: Theory, research, and commentary (pp.119-141) Mahwah, NJ: Erlbaum.

Faerch, C., \& Kasper, G. (1986). Cognitive Dimensions of Language Transfer. In E. Kellerman, \& M. S. Sharwood Smith, (Eds.), Crosslinguistic Influence in Second Language Acquisition (pp. 49-65). New York, USA: Pergamon Press.

Farley, A.P. (2004). The relative effects of processing instruction and meaning-based output instruction'. In B. VanPatten, (Ed.), Processing instruction: Theory, research, and commentary (pp. 227-239). Mahwah, NJ: Lawrence Erlbaum.

Fillmore, L. W. (1976). The second time around: Cognitive and social strategies in second language acquisition, (Unpublished Doctoral Dissertation). Stanford University, Stanford, California.

Klein, W. (1986). Second Language Acquisition. Cambridge, England: Cambridge University Press.

Lee, J. (2004). On the generalizability, limits, and potential future directions of processing instruction research. In B. VanPatten, (Ed.), Processing instruction:

Theory, research, and commentary (pp.311-323). Mahwah, NJ: Erlbaum.

Lee, J., \& Benati, A. (2007). Delivering processing instruction in classrooms and in virtual contexts: Research and practice. London, England: Equinox.

Lee, J., \& Benati, A. (2009). Research and perspectives on processing instruction. Berlin: Mouton de Gruyter.

Lee, J., \& VanPatten, B. (1995). Workbook to accompany making communicative language teaching happen. New York, USA: McGraw-Hill.

LoCoco, V. (1987). Learner comprehension of oral and written sentences in German and Spanish: the importance of word order. In B. VanPatten, T. Dvorak, \& J. F. Lee, (Eds.), Foreign Language Learning: A Research Perspective (pp.119-129). Rowley, MA: Newbury House.

Sanz, C. (1997). Experimental tasks in SLA research: Amount of production, modality, memory, and production processes.” In A. T. Pérez-Leroux, \& W. R. Glass (Eds.), Contemporary perspectives on the acquisition of Spanish: Production, processing and comprehension (pp. 41-56). Somerville, MA: Cascadilla Press. 
Sanz, C. (2004). Computer delivered implicit versus explicit feedback in processing instruction. In B. VanPatten, (Ed.), Processing instruction: Theory, research, and commentary (pp.241-255). Mahwah, NJ: Erlbaum.

Sanz, C., \& Morgan-Short, K. (2004). Positive evidence versus explicit rule presentation and explicit negative feedback: A computer-assisted study. Language Learning, 54(1), 35-78. DOI: 10.1111/j.1467-9922.2004.00248.x

VanPatten, B. (1996). Input processing and grammar instruction: Theory and research. Norwood, NJ: Ablex.

Van Patten, B. (2002). Processing instruction: An update. Language Learning, 52(4), 755 803.

VanPatten, B. (2004). Processing instruction: Theory, research, and commentary. Mahwah, New Jersey: Lawrence Erlbaum Associates

VanPatten, B. (2015). Foundations of processing. International Review of Applied Linguistics, 53, 91-109.

VanPatten, B., \& Cadierno, T. (1993). Explicit instruction and input processing. Studies in Second Language Acquisition, 15, 225-241.

VanPatten, B., \& Oikennon, S. (1996). Explanation vs. structured input in processing instruction. Studies in Second Language Acquisition, 18, 495-510.

VanPatten, B., \& Sanz, C. (1995). From input to output: Processing instruction and communicative tasks. In F.R. Eckman, D. Highland, P.W. Lee, \& J. Mileham,

R. R. Weber (Eds.), Second language acquisition theory and pedagogy (pp.169-185). Mahwah, NJ: Erlbaum.

VanPatten, B., \& Wong, W. (2004). Processing instruction and the French causative: Another replication. In B. VanPatten (Ed.), Processing instruction: Theory, research, and commentary (pp.99-120) Mahwah, NJ: Erlbaum.

Wong, W. (2004). Processing instruction in French: The roles of explicit information and structured input. In B. VanPatten (Ed.), Processing instruction: Theory, research, and commentary (pp. 187-205) Mahwah, NJ: Erlbaum.

Wong, W., \& Ito, K. (2018). The effects of processing instruction and traditional instruction on L2 online processing of the causative construction in French: An eye-tracking study. Studies in Second Language Acquisition 40(2), 241-268. Doi:10.1017/S0272263117000274

Appendix A:

Sample:

\section{Discourse Level Production Test (Version A).}

Discourse Level Production Task:

You will hear a story once, which will also be projected on the whiteboard. When the projector is turned off. You will be asked to re-write it with the help of the prompts provided to you. You have also been given some words; please write their definition before the story begins. If you still have unknown words in the following story you can ask your instructor after you listen to it. 
"Amal is a very good girl. She always takes good care of her bedroom and makes sure that it is clean and tidy. However, during the exams she becomes so busy, so her mother helps her..."

Amal came from school. She had her bed tidied. She hanged her dress in the cupboard. She had her desk dusted. She put her school books on the bookshelf to study later on. She had her flowers watered and her goldfish fed. She had the windows cleaned, so she opened the curtains. She was so happy that her room was clean and tidy, so she can study all day comfortably.

\title{
Version A: \\ Discourse Level Production Task:
}

Name:

Give the definitions of the following words. Ask your instructor for help if you need any. Then re-write the story you heard.

Dusted $=$

Fed $=$

Watered $=$

"Amal is a very good girl. She always takes good care of her bedroom and makes sure that it is clean and tidy. However, during the exams she becomes so busy, so her mother helps her..."

\section{Appendix B: Sample:}

\section{Discourse-Level Interpretation Task (Version A).}

\author{
Instructor's script \\ VERSION A \\ (Corresponding pages on students' test: $2-5$ ) \\ Sara's trip to Egypt. \\ Segment 1 (pictures:1-5, page:3)
}

Sara was so excited because the summer holiday began. After a long semester and passing all of her exams. She and her family were busy preparing for their trip to Egypt. She prepared her luggage. She had the tickets booked online. She had a list of interesting places written on a paper, she really wanted to see the pyramids. She had a tour guide called and informed about the places they were interested in visiting. She also had a suit reserved in a hotel on the Nile.

Segment 2 (pictures:6-10, page:4)

They all enjoyed their vacation in Egypt. Sara took many pictures for the pyramids. She had many souvenirs bought for her relatives. She had delicious lunch served in a restaurant on the Nile. She wore sunglasses because she spent most of her time outdoors. Finally, she had the car driven back to their hotel for them to rest. Segment 3 (pictures:11-15, page:5)

After their vacation was over, Sara and her family had the car driven to the airport. They went to a café waiting for the airplane to arrive. Sara had a terrible headache. So, she had a cup of coffee poured. She took a final selfie to remember her vacation. Finally, she sat beside the window to enjoy the view.

\section{VERSION A}


Arab World English Journal (AWEJ) Volume 12. Number 1. March 2021

Structured Input vs. Structured Output Task's Effects on the Acquisition

Alabdullah

DISCOURSE INTERPRETATION TASK

NAME:

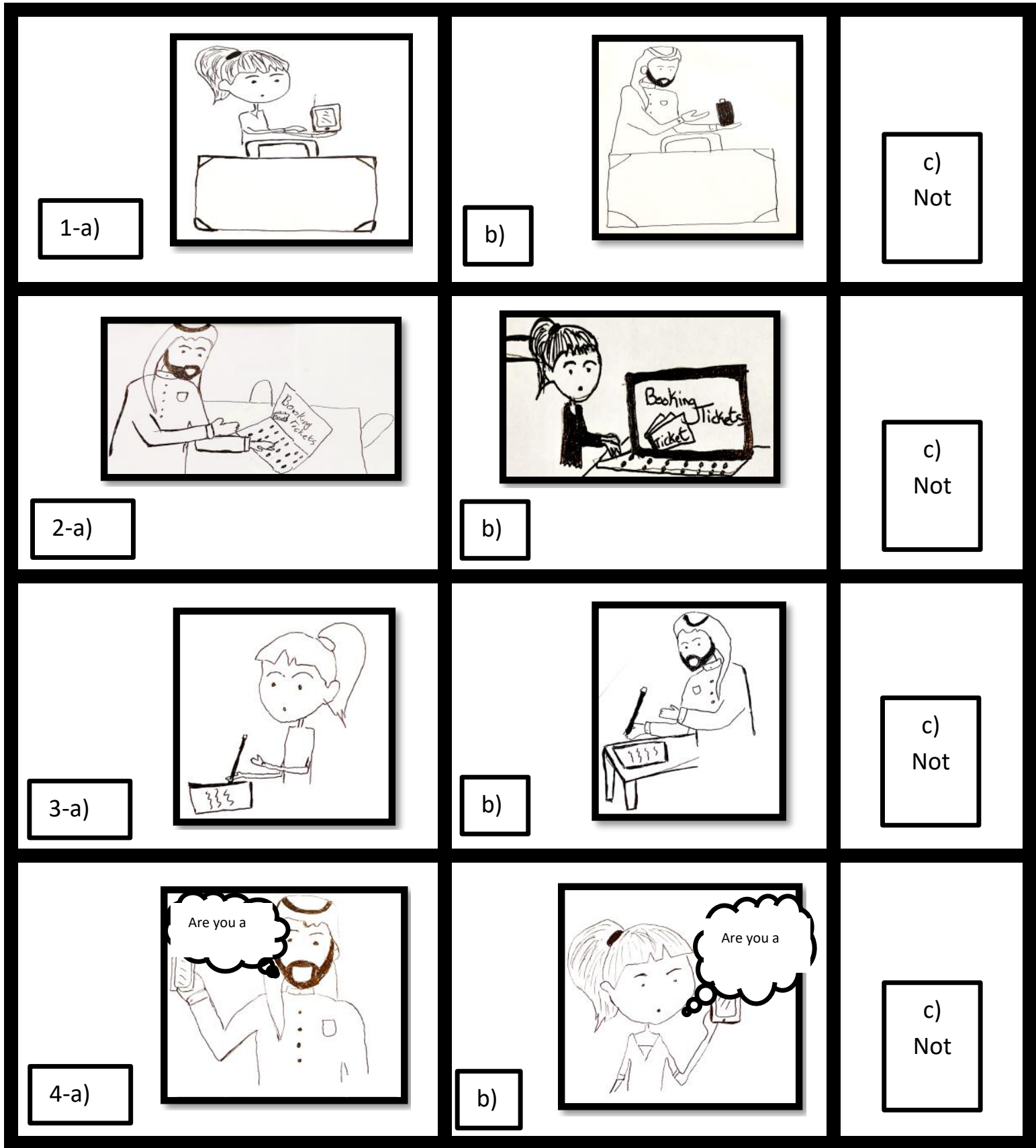


Arab World English Journal (AWEJ) Volume 12. Number 1. March 2021

Structured Input vs. Structured Output Task's Effects on the Acquisition

Alabdullah
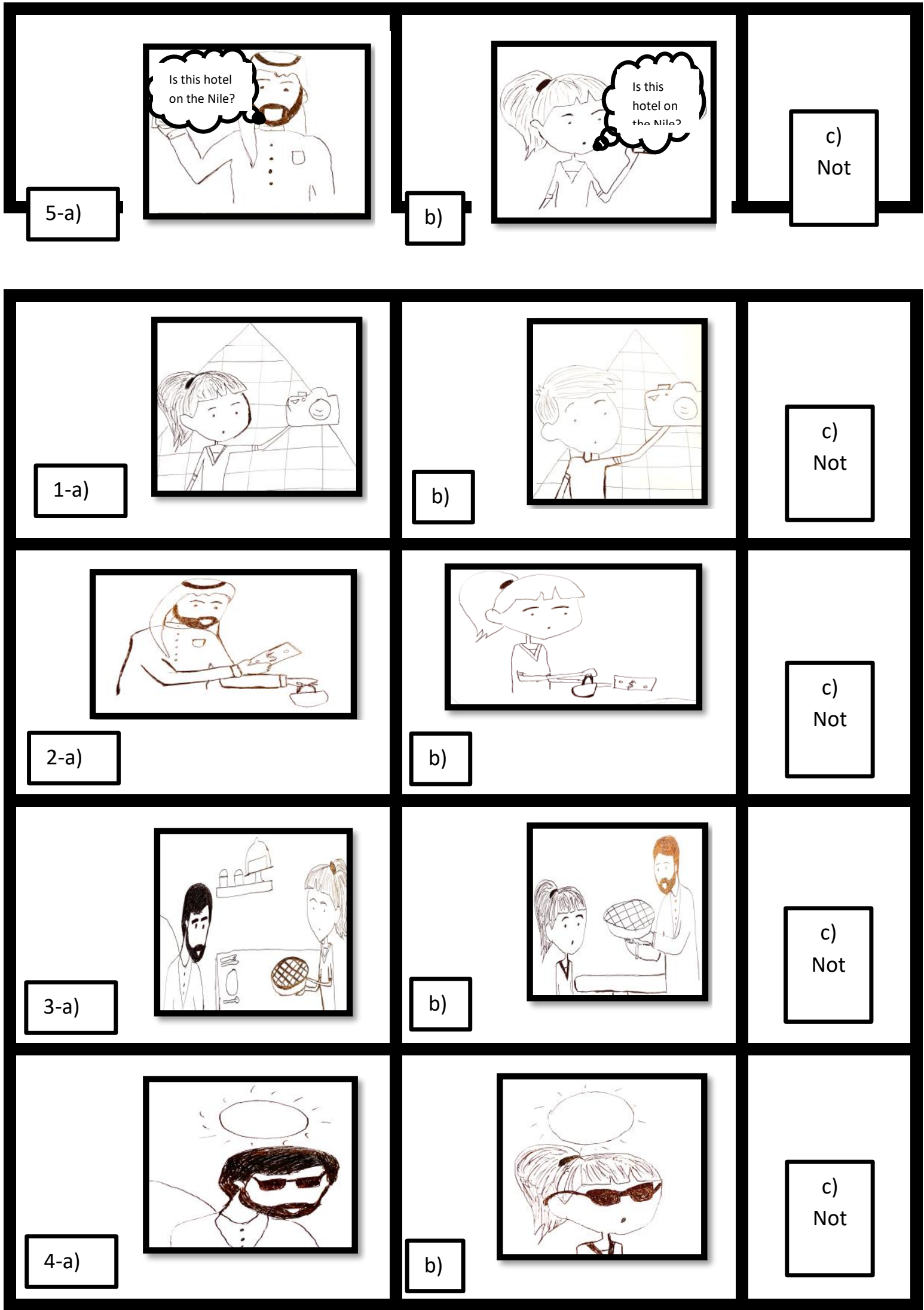

Arab World English Journal

ISSN: 2229-9327 
Arab World English Journal (AWEJ) Volume 12. Number 1. March 2021

Structured Input vs. Structured Output Task's Effects on the Acquisition

Alabdullah
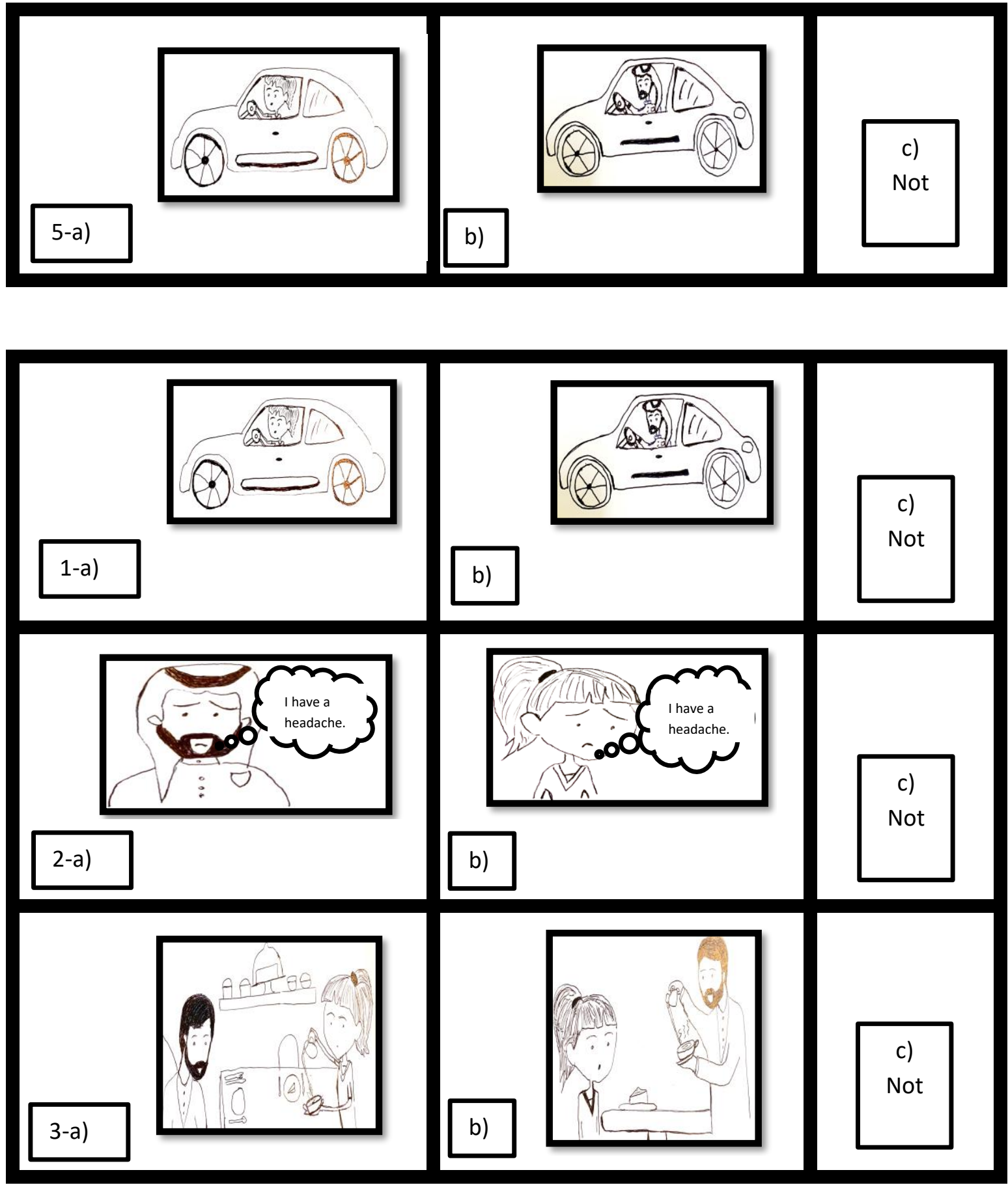
Arab World English Journal (AWEJ) Volume 12. Number 1. March 2021

Structured Input vs. Structured Output Task's Effects on the Acquisition

Alabdullah

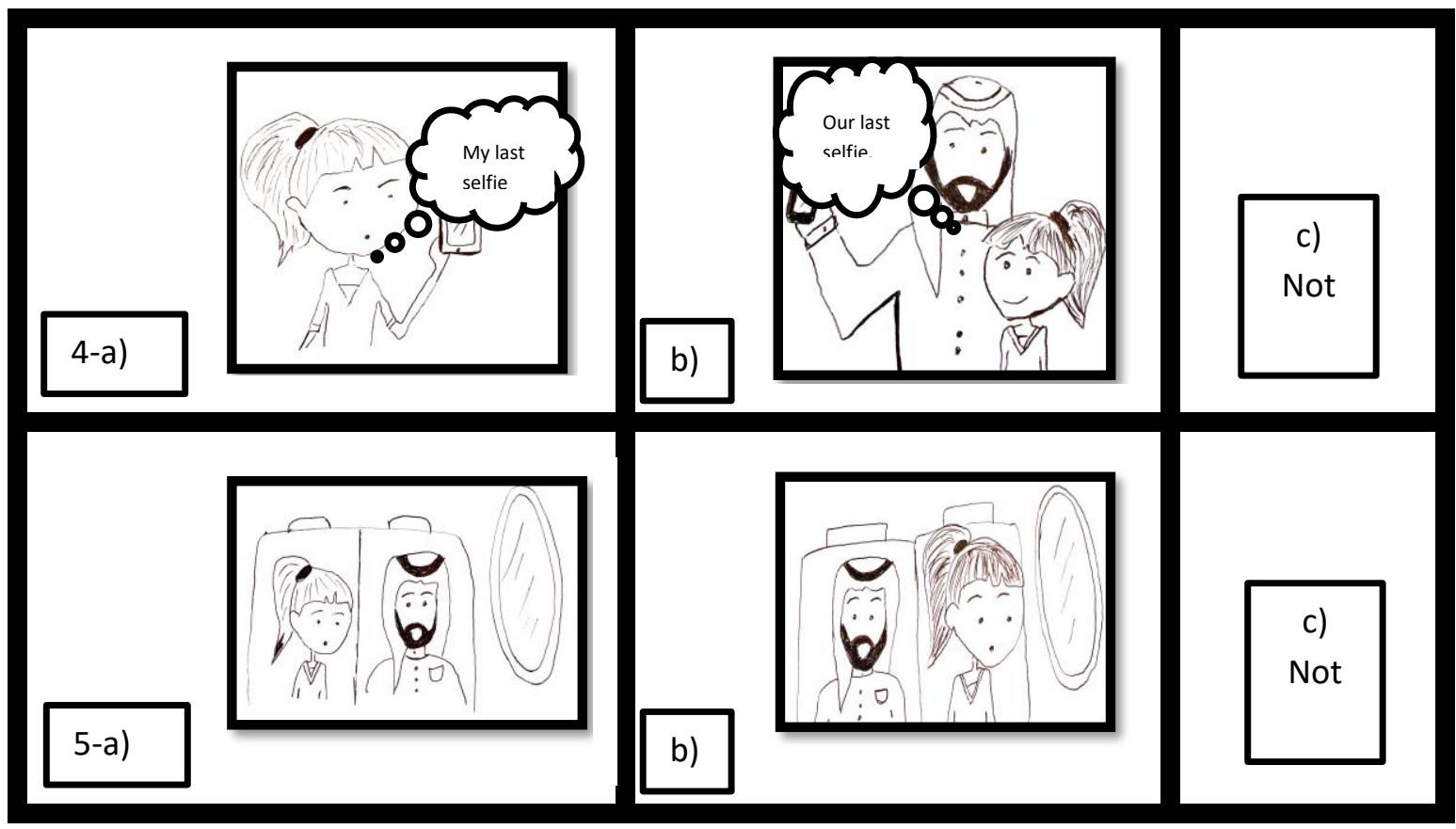

